ORIGINAL ARTICLE

\title{
Arc and resistance welding and tumours of the endocrine glands: a Swedish case-control study with focus on extremely low frequency magnetic fields
}

\author{
N Håkansson, C Stenlund, P Gustavsson, C Johansen, B Floderus
}

Occup Environ Med 2005;62:304-308. doi: 10.1136/oem.2004.015479

See end of article for authors' affiliations

.....................

Correspondence to: Dr N Håkansson, Institute of Environmental Medicine, Karolinska Institutet, Box 210, 17177 Stockholm, Sweden; niclas.hakansson@imm. ki.se

Accepted

1 November 2004

\begin{abstract}
Background: Mechanisms for potential effects of extremely low frequency (ELF) magnetic fields on carcinogenesis have not been identified. A potential pathway could be an interaction with the endocrine system.

Aims: To analyse occupational exposure to ELF magnetic fields from welding, and tumours of the endocrine glands.

Methods: This case-control study was based on a cohort with an increased prevalence of high exposed individuals. A total of 174 incident cases of tumours of the endocrine glands, 1985-94, were identified and data were obtained from 140 (80\%) of these cases; 1692 controls frequency matched on sex and age were selected, and information on 1306 (77\%) individuals was obtained. A short questionnaire was sent to a work administrator at the workplaces of the cases and controls. The exposure assessment was based on questions about job tasks, exposure to different types of welding, and exposure to solvents.

Results: There was an overall increased risk for all tumours of the endocrine glands for individuals who had been welding sometime during the follow up. The increased risk was attributable to arc welding; for resistance welding there was no clear evidence of an association. We found an increased risk for the adrenal glands in relation to arc welding, and for the parathyroid glands in relation to both arc welding and resistance welding. An imprecise increase in risk was also noted for tumours of the pituitary gland for arc welding. No confounding effect was found for solvent exposure, and there was no sign of biological interaction.

Conclusion: The increased risks of endocrine gland tumours related to welding might be explained by exposure to high levels of ELF magnetic fields.
\end{abstract}

B iological mechanisms for potential effects of extremely low frequency (ELF) magnetic fields on carcinogenesis have not been identified. It is unlikely that exposure to ELF magnetic fields is genotoxic. The associations observed between ELF magnetic fields and cancer in epidemiological studies, are rather due to a promoter or progressor effect than initiation, if the associations reflect a causal relation. ${ }^{1}$ Hormonal factors have been discussed as a link between ELF magnetic field exposure and cancer development. A potential influence from ELF magnetic fields on the pineal gland, with a decrease in the secretion of melatonin, subsequently affecting oestrogen levels, which might effect cancer development, for example, breast cancer, has been suggested..$^{2}$ The experimental evidence of an influence from ELF magnetic fields on melatonin in humans is weak, but some occupational studies have shown decreased levels of melatonin in high exposed workers. ${ }^{4-6}$ Most occupational studies on ELF magnetic fields and breast cancer do not show an association, but some studies have indicated an effect, particularly for premenopausal breast cancer in women ${ }^{7-10}$ and male breast cancer. ${ }^{11-14}$ There are also results suggesting an increased risk of tumours of the pituitary gland in high exposed individuals, ${ }^{15}$ and in certain occupational groups with high levels of ELF magnetic fields ${ }^{14}$. The aetiology of tumours of the endocrine glands is largely unknown, but pituitary tumours, for example, are thought to be dependent on excessive hormonal (hypothalamic) stimulation. ${ }^{16}$ Since the hormonal system seems to be a common denominator for breast cancer and endocrine tumours, a potential pathway between ELF magnetic fields and cancer development could be mediated by an interaction with the endocrine system. This interaction, if real, should be very complex. Laboratory studies on bioeffects of ELF magnetic fields have varied considerably; it has been suggested that the variability may be explained by a non-linear relation between exposure and the biological response. ${ }^{17}$

Tumours of the endocrine glands are often very small and go undetected, so-called micro adenomas. Hormones are not only thought to contribute to the development of endocrine tumours. The tumours are often, in turn, hormone secreting; pituitary tumours may produce prolactin, which seems to play an important role in female breast cancer development. ${ }^{18}$ Furthermore, in male breast cancer, prolactin (and pituitary adenoma) has been suggested to play an important role, based on case reports. ${ }^{19-21}$ Parathyroid tumours may secrete parathyroid hormone (PTH), and individuals with an increased secretion of PTH may run a higher risk of developing malignant tumours of different types. ${ }^{22-24}$

The aim of the present study was to analyse the risk of tumours of the endocrine glands in arc and resistance welders, using welding as a surrogate measure of exposure to ELF magnetic fields. Arc welding may produce ELF magnetic fields of a few hundred $\mu T_{e}{ }^{2}{ }^{25}$ and resistance welding may produce magnetic field densities that are even higher. ${ }^{26}$ Based on measurements of 13 randomly chosen welders, we found an average work shift arithmetic mean value of $1.90 \mu \mathrm{Tesla}$, and $142 \mu \mathrm{Tesla}$ as the average maximum value. ${ }^{27}$ Strengths of the study are that welding should yield marked contrasts of exposure to ELF magnetic fields, and that welding was assessed on an individual level. 


\section{Main messages}

- Exposure to welding was assessed on an individual level in a population based case-control study, comprising 140 incident cases of tumours of the endocrine glands. Welding was associated with a twofold increase in risk of tumours of the endocrine glands.

- A three- to fourfold increase in risk was observed for adrenal gland tumours and parathyroid gland tumours in arc welders. For resistance welding a relative risk estimated at 2.6 was found for parathyroid glands. No conclusive results were obtained for pituitary gland tumours.

- There was no confounding from solvent exposure. The link between welding and tumours of the endocrine glands might be mediated by exposure to high levels of electromagnetic fields.

\section{SUBJECTS AND METHODS \\ Study base}

This case-control study was based on a previously elaborated cohort with an increased prevalence of high exposed individuals, such as resistance welders. The cohort was established by linkage between a number of central registries. Firstly, industrial branches where resistance welding might take place were identified. The second step was to identify all companies and workplaces within these branches. The third and final step was to identify all persons ever employed at these companies and workplaces during the study period 1985-94. The cohort comprises 537692 men and 180529 women, and has previously been used in two different cohort studies on ELF magnetic field exposure, focusing on cancer diseases ${ }^{15}$ and neurodegenerative diseases. ${ }^{28}$ Both the previous cohort studies and the present case-control study have been approved by the Ethical Committee at the Karolinska Institutet, Stockholm, Sweden.

\section{Cases and controls}

Incident cases of tumours of the endocrine glands in the cohort as well as cases diagnosed with leukaemia, and tumours of the brain and breast during 1985-94 were obtained through matching with the Swedish Cancer registry. Here, we report the results on tumours of the endocrine glands.

In order to facilitate the data collection of the case-control study we restricted the study population and selected cases and controls from workplaces that met certain criteria: they should still exist at the time of the data collection; and have at least 10 employees some time during 1985-94, with at least one welder (ISCO job code 755) employed some time during that period. The final criterion was that at least one incident cancer case (all diagnoses mentioned above) should have occurred at the workplace during 1985-94. A total of 673 workplaces fulfilled these criteria on 1 January 1998.

One control per cancer case (with all the diagnoses mentioned above) was selected, frequency matched on age and sex. In all, 1692 controls were selected and information on $1306(77 \%)$ individuals was obtained. Since we assume that the exposure distribution of the entire control group reflects the exposure distribution of the study base of the target cases, we used all the controls in the analyses of endocrine tumours. A total of 174 cases of tumours of the endocrine glands were identified during 1985-94 and data were obtained from $140(80 \%)$ of these cases. The

\section{Policy implications}

- Two occupational groups, welders and train personnel, both known to be exposed to high levels of electromagnetic fields, have shown increased risks of endocrine gland tumours. This strengthens the hypothesis that occupational exposure to electromagnetic fields might contribute to hormone related cancer development.

- Additional research should explore in more detail the occurrence of potential confounding factors in these occupational settings, in order to find alternative explanations for the associations.

non-participation accounted for $22 \%$ of the original study size and was mainly due to a few large companies refusing to participate. Seventy one per cent of the drop out was attributed to companies that did not participate in the study; the remaining $29 \%$ were due to individual reporting failure within participating companies. The 140 cases of tumours of the endocrine glands were distributed on adrenal glands $(\mathrm{n}=29)$, parathyroid gland $(\mathrm{n}=67)$, pituitary gland $(n=36)$, and other subtypes $(n=8)$. The mean age of the cases was 49.7 years (median 51) and the mean age among the controls was 51.4 (median 53).

\section{Data collection}

A two page questionnaire and a list of the cases/controls employed at a workplace were sent to a contact person (personnel administrator/work supervisor) of the workplace in question. Subsequently, the data were collected by telephone interviews with the contact person. This allowed the contact person to go through the list of individuals and to seek exposure information when necessary. The individual's case-control status was not revealed.

\section{Exposure assessment}

The exposure assessment was based on questions about years of employment during 1985-94, job tasks, exposure to welding, type of resistance welding (spot, flash, butt, seam, and projection welding) and arc welding, as well as estimated hours of exposure per week during these years. Corresponding questions on solvent exposure were also included.

The results presented include analyses that were based on the mean number of hours of welding (per week) over the years of follow up. The exposure measure was calculated from the combined information on number of years of follow up and welding hours per week during these years. If, for example, an individual was welding 40 hours a week (that is, full time) for all the years he/she was followed (see statistical methods) then his/hers exposure level was set to 40 hours of welding per week on average. An individual followed for two years who had been welding 40 hours/week the first year and 20 hours/week the second year would get 30 hours of welding per week on average. If a subject had missing data for a year during follow up, which was the case for $4 \%$ of the subjects, we lagged the data from the last previous year with known exposure information.

\section{Statistical methods}

All controls were used in the analysis. Risk sets were formed by creating sets with one case per set and then randomising the eligible controls to each case within strata of sex and year of birth (three year intervals). Control individuals who did not match any case $(n=184)$ were excluded from the 
Table 1 Odds ratios (OR) of all tumours of the endocrine glands in workers exposed to high levels of ELF magnetic fields from welding, Sweden 1985-94

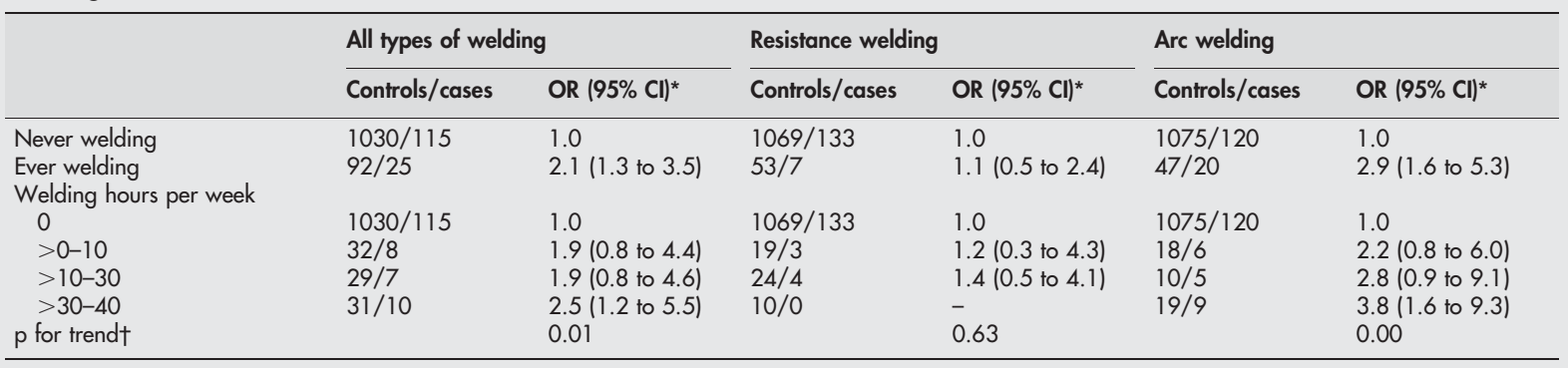

*Odds ratios (with $95 \%$ confidence intervals), adjusted for sex, year of birth, solvent exposure, and year of inclusion.

$\mathrm{tp}$ for trend is based on average hours of welding per week, used as a continuous variable in the logistic regression model.

analyses. Exposure information for controls was censored at the year of diagnosis of the corresponding case.

Relative risks were estimated by odds ratios (OR) from conditional logistic regression analyses, with the risk sets as strata and with additional control for solvent exposure and year of entry into the study base. We used three strata for year of entry: 1985, 1986, and 1987-94; these intervals were chosen because of the skewed distribution. All risk estimates were computed using the SAS software. ${ }^{29}$

We analysed a potential interaction between exposure to welding and solvents by testing if the joint effect was greater than the sum of the independent effects of each single factor by calculating the synergy index..$^{30}$

\section{RESULTS}

We found an overall increased risk of tumours of the endocrine glands for subjects who had been welding sometime during the follow-up (table 1). The increased risk was attributable to arc welding and for resistance welding there was no support for an association.

For the different subtypes of endocrine glands, we found an increased risk for adrenal glands in relation to arc welding, and for parathyroid glands in relation to both arc welding and resistance welding (table 2). For the pituitary gland we observed an imprecise but increased risk for arc welding only.

The analysis of average welding hours per week yielded some results that were consistent with an exposure-response association. This was most pronounced for all endocrine tumours combined especially among arc welders (table 1), but also for tumours of the parathyroid glands $(p<0.01)$, both for arc welders and all types of welding (not shown in table). We did not observe any conclusive results as to exposure-response patterns among resistance welders.

With regard to solvent exposure we observed an association between ever exposed and tumours of the adrenal glands $(\mathrm{OR}=3.2,95 \%$ CI 1.0 to 10.3$)$. The analysis of interaction between welding and exposure to solvents did not reveal any biological interaction-that is, all the synergy indices were below 1.0. However, the number of cases in the subgroups was small, yielding limited power for the analysis of synergy indices.

\section{DISCUSSION}

The effect among welders was attributed to arc welding and not to resistance welding, which was contrary to our expectations. Resistance welding is generally characterised by even higher ELF magnetic fields than those observed for arc welding. These welders are exposed to magnetic fields from currents as high as 100000 amperes. ${ }^{26}$ Electric arc welding is also known to cause considerable exposure to ELF magnetic fields from currents in the range of 100-500 amperes. ${ }^{31}$ It could be, however, that the exposure to the head and neck region may be even higher for arc welding than for resistance welding, because the arc welder often carries (carried) the cable over the shoulder, ${ }^{31}$ which should be particularly close to the parathyroid glands. For parathyroid glands the risk was increased among resistance welders, but again, the association was stronger for arc welders. To some extent, the difference between the two types of welding is explained by a small number of cases and a low prevalence of resistance welding.

When we previously analysed tumours of the endocrine glands in relation to exposure to ELF magnetic fields in the cohort on which this case-control study was based, we found an increased risk for pituitary gland tumours among men in the highest exposure group, $>0.53 \mu \mathrm{T}$, RR 2.4 (0.9 to 6.2$).{ }^{15}$ An increased risk for tumours of the adrenal glands was also suggested among women, but the result was based on few cases. The case-control study partly supports the hypothesis of an association with tumours of the endocrine glands generated by the cohort study, but there are discrepancies regarding the specific tumour locations involved. An explanation to the differences might be the different methods of

Table 2 Odds ratios (OR) for subtypes of tumours of the endocrine glands in workers exposed to high levels of ELF magnetic fields from welding, Sweden 1985-94

\begin{tabular}{|c|c|c|c|c|c|c|c|}
\hline \multirow[b]{2}{*}{ Subtype } & \multirow[b]{2}{*}{ Welding } & \multicolumn{2}{|c|}{ All types of welding } & \multicolumn{2}{|c|}{ Resistance welding } & \multicolumn{2}{|l|}{ Arc welding } \\
\hline & & Controls/cases & OR $(95 \% \mathrm{Cl})^{*}$ & Controls/cases & OR $(95 \% \mathrm{Cl})^{*}$ & Controls/cases & OR $(95 \% \mathrm{Cl})^{*}$ \\
\hline Adrenal gland & Never & $199 / 24$ & 1.0 & $206 / 29$ & 1.0 & $210 / 24$ & 1.0 \\
\hline \multirow[t]{2}{*}{ Pituitary gland } & Never & $258 / 31$ & 1.0 & $272 / 35$ & 1.0 & $273 / 32$ & 1.0 \\
\hline & Ever & $32 / 5$ & 1.4 (0.5 to 4.2$)$ & $18 / 1$ & 0.5 (0.1 to 4.2$)$ & $17 / 4$ & $1.8(0.5$ to 6.2$)$ \\
\hline \multirow[t]{2}{*}{ Parathyroid gland } & Never & $542 / 53$ & 1.0 & $558 / 61$ & 1.0 & $561 / 57$ & \\
\hline & Ever & $37 / 14$ & $3.3(1.6$ to 6.9$)$ & $21 / 6$ & $2.6(0.9$ to 7.1$)$ & $18 / 10$ & $4.3(1.7$ to 10.6$)$ \\
\hline
\end{tabular}

*Odds ratios (with 95\% confidence intervals), adjusted for sex, year of birth, solvent exposure, and year of inclusion. 
exposure assessment. In the cohort analysis we used the subject's occupational codes from the censuses and linked them to a job exposure matrix..$^{27}$ The exposure assessment on the individual level that was applied in the case-control study should be less influenced by misclassification. For example, we should have also captured people exposed to welding when there was no indication of such exposure according to the occupational codes recorded in the censuses. The differences could also be due to inconsistencies regarding the nature of high exposure in the two studies. High exposed individuals in the cohort analyses comprised not only welders but also several other occupations.

There seems to be no established environmental risk factors for tumours of the endocrine glands other than iodine deficiency and ionising radiation relative to thyroid carcinoma (not considered in the current study). ${ }^{32}$ We considered solvent exposure as the most probable confounder. Controlling for solvents did not change the results to any significant extent. Arc welding is accompanied by exposure to welding fumes (for example, nickel and chromium ${ }^{33}$ ) and UV radiation, ${ }^{34}$ and confounding from these factors, for example, cannot be dismissed.

A strength of the study was that the exposure was assessed on an individual level without a potential for recall bias of the study individuals. Nevertheless, the study may in theory suffer from misclassification of the exposure, but the potential for differential bias should be limited. The casecontrol status was not disclosed to the representatives of the companies/workplaces. If the informant knew about the disease of an employee, which could produce bias, we see no reason why he/she should then overstate welding and not solvent exposure as well. We did not observe any convincing association for solvent exposure, other than an increased risk estimate for adrenal tumours.

Non-participation may introduce selection bias. The drop out was largely attributed to some big companies. Their refusals were motivated by lack of resources for participation. It seems unlikely that these companies should have characteristics that would modify the effect and change the results. The main disadvantage caused by the non-participation was probably the reduced statistical power.

The age standardised incidence of tumours of the endocrine glands considered (ICD-7 code 195) increased in Sweden from less than 2 cases per 100000 person years around 1960 to about 11 per 100000 during the middle of the 1990 s among women. Corresponding numbers for men were 2 cases to close to 6 per 100000 (derived from data provided by the Swedish cancer registry). For the last five year period a drop in incidence can be noticed, however. ${ }^{35}$ Advanced diagnostics and a wider application of imaging techniques should be the main explanation for the increase, but part of the trend might of course be explained by an increased incidence of these tumours.

\section{Conclusion}

The study showed a twofold increase in risk of tumours of the endocrine glands in workers exposed to arc or resistance welding. Welding was assessed on an individual level, and these processes are known to entail extremely high levels of ELF magnetic fields. The link between welding and tumours of the endocrine glands might be mediated by exposure to high levels of ELF magnetic fields. The association was not explained by confounding from solvent exposure, but confounding from other factors cannot be dismissed.

\section{ACKNOWLEDGEMENTS}

The study was financially supported by the Swedish Council for Working Life and Social Research, grant no. 2002-0463.

\section{Authors' affiliations}

N Håkansson, Division of Environmental Epidemiology, Institute of Environmental Medicine, Karolinska Institutet, Stockholm, Sweden C Stenlund, B Floderus, National Institute for Working Life, Stockholm, Sweden

P Gustavsson, Department of Occupational and Environmental Health, Stockholm Centre for Public Health, Stockholm, Sweden

C Johansen, Institute of Cancer Epidemiology, Danish Cancer Society, Copenhagen, Denmark

\section{REFERENCES}

1 Portier C, Wolfe M. Assessment of health effects from exposure to power-line frequency electric and magnetic fields, NIEHS Working Group Report. Triangle Park: NIH Publication, 1998.

2 Stevens RG. Electric power use and breast cancer: a hypothesis. Am J Epidemiol 1987;125:556-61.

3 Baldwin WS, Barrett JC. Melatonin: receptor-mediated events that may affect breast and other steroid hormone-dependent cancers. Mol Carcinog 1998;21:149-55.

4 Burch JB, Reif JS, Yost MG, et al. Nocturnal excretion of a urinary melatonin metabolite among electric utility workers. Scand J Work Environ Health 1998;24:183-9.

5 Burch JB, Reif JS, Yost MG, et al. Reduced excretion of a melatonin metabolite in workers exposed to $60 \mathrm{~Hz}$ magnetic fields. Am J Epidemiol 1999;150:27-36

6 Burch JB, Reif JS, Noonan CW, et al. Melatonin metabolite levels in workers exposed to $60-\mathrm{Hz}$ magnetic fields: work in substations and with 3-phase conductors. J Occup Environ Med 2000;42:136-42.

7 Loomis DP, Savitz DA, Ananth CV. Breast cancer mortality among female electrical workers in the United States. J Natl Cancer Inst 1994;86:921-5.

8 Coogan PF, Clapp RW, Newcomb PA, et al. Occupational exposure to 60hertz magnetic fields and risk of breast cancer in women. Epidemiology 1996;7:459-64.

9 Forssén UM, Feychting $M$, Rutqvist LE, et al. Occupational and residential magnetic field exposure and breast cancer in females. Epidemiology 2000;11:24-9.

10 Van Wijngaarden E, Nylander-French LA, Millikan RC, et al. Populationbased case-control study of occupational exposure to electromagnetic fields and breast cancer. Ann Epidemiol 2001;11:297-303.

11 Matanoski GM, Breysse PN, Elliott EA. Electromagnetic field exposure and male breast cancer. Lancet 1991;337:737.

12 Demers PA, Thomas DB, Rosenblatt KA, et al. Occupational exposure to electromagnetic fields and breast cancer in men. Am J Epidemiol $1991 ; 134: 340-7$

13 Tynes T, Andersen A, Langmark F. Incidence of cancer in Norwegian workers potentially exposed to electromagnetic fields. Am J Epidemiol 1992;136:81-8.

14 Floderus B, Törnqvist S, Stenlund C. Incidence of selected cancers in Swedish railway workers, 1961-79. Cancer Causes Control 1994;5:189-94.

15 Håkansson N, Floderus B, Gustavsson P, et al. Cancer incidence and magnetic field exposure in industries using resistance welding in Sweden. Occup Environ Med 2002;59:481-6.

16 Korbonits M, Morris DG, Nanzer A, et al. Role of regulatory factors in pituitary tumour formation. Front Horm Res 2004;32:63-95.

17 Marino AA, Wolcott RM, Chervenak R, et al. Coincident nonlinear changes in the endocrine and immune systems due to low-frequency magnetic fields. Neuroimmunomodulation 2001;9:65-77.

18 Clevenger CV, Furth PA, Hankinson SE, et al. The role of prolactin in mammary carcinoma. Endocr Rev 2003;24:1-27.

19 Volm MD, Talamonti MS, Thangavelu M, et al. Pituitary adenoma and bilateral male breast cancer: an unusual association. J Surg Oncol 1997;64:74-8

20 Forloni F, Giovilli M, Pecis C, et al. Pituitary prolactin-secreting macroadenoma combined with bilateral breast cancer in a 45 -year-old male. J Endocrinol lnvest 2001;24:454-9.

21 Okada K, Kajiwara S, Tanaka H, et al. Synchronous bilateral noninvasive ductal carcinoma of the male breast: a case report. Breast Cancer 2003; 10:163-6.

22 Hall K, Siögren B. Binjurebarkens sjukdomar [in Swedish]. In: Hallberg L, Holm G, Lindholm N, Werkö L, eds. Internmedicin. Stockholm: Almqvist \& Wiksell Förlag AB, 1991.

23 Hall K, Siögren B. Hypofysens sjukdomar [in Swedish]. In: Hallberg L, Holm G, Lindholm N, Werkö L, eds. Internmedicin. Stockholm: Almqvist \& Wiksell Förlag $A B, 1991$.

24 Hall K, Sjögren B. Bisköldkörtlarnas sjukdomar [in Swedish]. In: Hallberg L, Holm G, Lindholm N, Werkö L, eds. Internmedicin. Stockholm: Almqvist \& Wiksell Förlag $A B, 1991$.

25 Stuchly MA, Lecuyer DW. Exposure to electromagnetic fields in arc welding. Health Phys 1989;56:297-302.

26 Weman K. Svetshandbok [Swedish]. Karlebo-serien. Göteborg: Liber, 1997:256.

27 Floderus B, Persson T, Stenlund C. Magnetic field exposures in the workplace: reference distribution and exposure in occupational groups. Int $J$ Occup Environ Health 1996;2:226-38.

28 Håkansson N, Gustavsson P, Johansen C, et al. Neurodegenerative diseases in welders and other workers exposed to high levels of magnetic fields. Epidemiology 2003;14:420-6.

29 SAS Software. Cary, NC, USA: SAS Institute Inc, 2001 
30 Rothman KJ. Modern epidemiology. Boston, MA: Little, Brown and Company, 1986.

31 Skotte JH, Hjollund HI. Exposure of welders and other metal workers to ELF magnetic fields. Bioelectromagnetics 1997; 18:470-7.

32 Monson JP. The epidemiology of endocrine tumours. Endocr Relat Cancer 2000;7:29-36.
33 IARC. Chromium, nickel and welding. IARC Monographs on the Evaluation of Carcinogenic Risks to Humans. Vol. 49. Lyon, France: IARC Press, 1990:677. 34 Tenkate TD, Collins MJ. Personal ultraviolet radiation exposure of workers in a welding environment. Am Ind Hyg Assoc J 1997:58:33-8.

35 Anon. Folkhälsan i Siffror [Swedish]. Stockholm: The Center for Epidemiology at The National Board of Health and Welfare, 2003.

\section{Clinical Evidence - Call for contributors}

Clinical Evidence is a regularly updated evidence-based journal available worldwide both as a paper version and on the internet. Clinical Evidence needs to recruit a number of new contributors. Contributors are healthcare professionals or epidemiologists with experience in evidence-based medicine and the ability to write in a concise and structured way.

Areas for which we are currently seeking authors:

- Child health: nocturnal enuresis

- Eye disorders: bacterial conjunctivitis

- Male health: prostate cancer (metastatic)

- Women's health: pre-menstrual syndrome; pyelonephritis in non-pregnant women

However, we are always looking for others, so do not let this list discourage you.

Being a contributor involves:

- Selecting from a validated, screened search (performed by in-house Information Specialists) epidemiologically sound studies for inclusion.

- Documenting your decisions about which studies to include on an inclusion and exclusion form, which we keep on file.

- Writing the text to a highly structured template (about 1500-3000 words), using evidence from the final studies chosen, within 8-10 weeks of receiving the literature search.

- Working with Clinical Evidence editors to ensure that the final text meets epidemiological and style standards.

- Updating the text every six months using any new, sound evidence that becomes available. The Clinical Evidence in-house team will conduct the searches for contributors; your task is simply to filter out high quality studies and incorporate them in the existing text.

- To expand the topic to include a new question about once every 12-18 months.

If you would like to become a contributor for Clinical Evidence or require more information about what this involves please send your contact details and a copy of your CV, clearly stating the clinical area you are interested in, to Klara Brunnhuber (kbrunnhuber@ bmigroup.com).

\section{Call for peer reviewers}

Clinical Evidence also needs to recruit a number of new peer reviewers specifically with an interest in the clinical areas stated above, and also others related to general practice. Peer reviewers are healthcare professionals or epidemiologists with experience in evidence-based medicine. As a peer reviewer you would be asked for your views on the clinical relevance, validity, and accessibility of specific topics within the journal, and their usefulness to the intended audience (international generalists and healthcare professionals, possibly with limited statistical knowledge). Topics are usually 1500-3000 words in length and we would ask you to review between 2-5 topics per year. The peer review process takes place throughout the year, and our turnaround time for each review is ideally 10-14 days.

If you are interested in becoming a peer reviewer for Clinical Evidence, please complete the peer review questionnaire at www.clinicalevidence.com or contact Klara Brunnhuber (kbrunnhuber@bmigroup.com). 